\title{
Genesis of Clay Rock of the Incomplete Stage of Mineral Formation as a Raw Material Base for Autoclaved Materials
}

\author{
A. Volodchenko ${ }^{(\bowtie)}$ and V. Strokova \\ Belgorod State Technological University named after V.G. Shukhov, \\ Belgorod, Russia \\ volodchenko@intbel.ru
}

\begin{abstract}
We illustrated possible application of clay rock of incomplete stage of mineral formation to produce autoclaved silica materials. A distinguishing feature of this rock was the presence of thermodynamically unstable compounds. Weathering processes resulted in partial disintegration of the rock, formation of defects in the crystalline lattice of the rock-forming minerals, and partial amorphization of both silicates and aluminosilicates, which reduced the energy potential of the raw materials. Thus, it was possible to use hydrothermal conditions to boost the formation of neogeneses of cementing compounds and reduce power consumption of the production of autoclaved materials.
\end{abstract}

Keywords: Lime $\cdot$ Clay rock $\cdot$ Autoclaved silica

\section{Introduction}

The traditional technology of manufacturing of silica materials is based on using lime and silica sand as raw materials, and the reserves of the latter are getting depleted. Furthermore, this technology is marked with a high power consumption. The consumption of power for grinding the binder and hydrothermal treatment can be reduced by using highly reactive polymineral raw materials, which would allow not only to replace silica sand but also intensify the technological processes. A prospective raw material for producing autoclaved silica materials is the clay rock of the incomplete stage of mineral formation, which is currently unconventional in the building industry (Lesovik 2012; Lesovik et al. 2014; Alfimova and Shapovalov 2013; Volodchenko et al. 2015; Volodchenko et al. 2016; Alfimov et al. 2006; Alfimova et al. 2013). As compared with the traditional silica sand, this rock ensures the synthesis of neogeneses in a more complex system " $\mathrm{CaO}-\left[\mathrm{SiO}_{2}-\mathrm{Al}_{2} \mathrm{O}_{3}-(\mathrm{MgO})\right]-\mathrm{H}_{2} \mathrm{O}$ ", which the reduction of power consumption of manufacturing and improving physical, mathematical, and performance properties of both solid and cellular autoclaved materials (Volodchenko and Lesovik 2008a, 2008b; Volodchenko 2011).

The purpose of this paper is to study the genesis of clay rock of the incomplete stage of mineral formation as raw material for producing autoclaved silica materials. 


\section{Results and Discussion}

Some of the most proliferated rocks are deposits of clay. They are formed through weathering of igneous and metamorphic rocks.

The process of weathering of felsic rock passes the following stages: physical weathering (clastic stage), start of the chemical weathering with illite formation (siallite stage), chemical weathering with kaolinite formation (acidic siallite stage), and complete decomposition of silicates with the formation of aluminum, ferrous, and silicon oxides (allite stage). Weathering of rock results in the formation of minerals predominantly of the montmorillonite group.

The processes of weathering can be represented as the destruction of the crystalline structure of the source minerals followed by a transfer through the pseudo-amorphous state and then the formation of the crystalline structure of new rock-forming minerals. However, the ideal amorphous (non-crystalline) state, as well as crystalline state, is not achieved and the transition through it is considered conditional. This results in the change of the source framework structure of the feldspar into the layered structure of clay minerals.

This transition results in rocks that can be characterized as products of the intermediary stage of weathering that occupy a significant stretch in the line of sub-stance transformation and predominate in nature. The rock-forming minerals of these formations include the X-ray amorphous phase, illites, mixed-layer minerals, and imperfectly structured kaolinite and montmorillonite. The formation of these compounds is accompanied by disordering of the crystalline structure of the source minerals, which increases the thermodynamic instability of the rock.

The rocks in the intermediary stage of weathering that were mechanically and chemically activated by exogenous geologic processes, i.e. those that belong to the starting stage of chemical weathering that results in the formation of defects in the structure of silicates and aluminosilicates and the formation of illites, are virtually never used. However, due to their thermodynamic instability, these rocks are the most efficient raw material as components of the systems that must be highly reactive. In particular, such rocks can be used as components of hydro-thermal curing binders, which allows to manage the processes of the formation of the structure of newgeneration autoclave materials.

Based on the data about the genesis of the weathering rind rocks, the processes of phase formation in artificial systems of autoclaved curing and how they compare with their natural counterparts of mineral formation, a diagram of the exogenous processes of the genesis of clay rocks as a raw material base for autoclaved materials is proposed (Fig. 1).

The rocks that formed after the second (siallite stage) and partially the third (acidic siallite) stage of weathering belong to the rocks of the incomplete stage of mineral formation that contain compounds of the intermediary stage of weathering: the source minerals have decomposed while the final ones have not formed yet. Such minerals are characterized by the presence of crystalline structure defects and, consequently, thermodynamic instability. This kind of rock can either remain at the place of its formation 


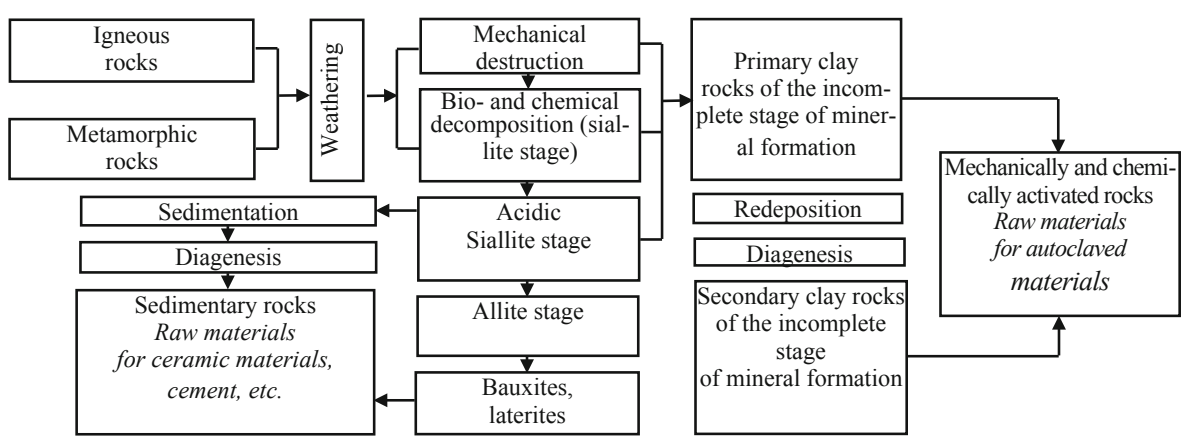

Fig. 1. Diagram of the exogenous processes of the genesis of clay rocks as raw materials base for autoclaved materials

or redeposit in new places as the result of transfer and diagenesis. These rocks are useful as raw materials for autoclaved curing materials.

Thus, weathering of source rocks of different compositions leads to the formation of mineral resources that are different in their composition and industrial significance. If one considers the weathering rind profile, it can be seen that at the moment the building materials industry is using the lower horizon (source rocks) and products of the final stage of weathering: kaolinite and montmorillonite clays as well as bauxites.

Clay rocks of the incomplete stage of mineral formation are some of the most inconsistent in terms of composition and the structure of the sedimentation mass deposits. In terms of the crystallochemical features of the rock-forming minerals, it is necessary to note the high content of the crystalline structure defects, the dis-order of the interlayer aluminosilicate stacks in the layered structure of minerals, etc. The crystalline lattice of the typical clay minerals that belong to layered silicates is characterized by the alteration of silicon-oxygen tetrahedra and hydroxyl octahedra. To some degree, clay minerals can be considered objects, where the nanoparticles (elementary layer packets) are packed into the microscopic structures, where the properties of the individual constituent particles are concealed due to a strong interparticle interaction.

\section{Conclusions}

Thus, lay rocks of the incomplete stage of mineral formation are energy-saturated deposits. Due to the composition and crystallochemical features of the rock-forming minerals, these rocks can be recommended as energy-efficient raw materials for the production of autoclaved curing materials. A distinguishing feature of this rock is the presence of thermodynamically unstable compounds. At the same time, aluminosilicates are characterized by variable chemical composition and the imperfection of their crystalline lattice. Weathering processes result in partial disintegration of rock, formation of defects in the crystalline lattice of the rock-forming minerals, and partial amorphization of both silicates and alumino-silicates, which reduces the energy 
potential of the rock-forming minerals. Thus, it is possible to use hydrothermal conditions to boost the formation of neogeneses of cementing compounds and reduce the power consumption of the production of autoclaved materials.

Acknowledgements. The work is realized in the framework of the Program of flagship university development on the base of the Belgorod State Technological University named after V.G. Shukhov, using equipment of High Technology Center at BSTU named after V.G. Shukhov.

\section{References}

Alfimov SI, Zhukov RV, Volodchenko AN, Yurchuk DV (2006) Technogenic raw materials for silicate hydration hardening. Mod High Technol 2:59-60

Alfimova NI, Shapovalov NN (2013) Materials autoclaved using man-made aluminosilicate materials. Fundam Res 6(3):525-529

Alfimova NI, Shapovalov NN, Abrosimova OS (2013) Operational characteristics of silica brick, manufactured using man-made aluminosilicate materials. Bulletin of BSTU named after V.G. Shukhov, vol 3, pp 11-14

Lesovik VS (2012) Geonik. Subject and tasks. Publisher Belgorod State Technological University. VG Shukhov, p 219

Lesovik VS, Volodchenko AA, Svinarev AA, Kalashnikov NV, Rjapuhin NV (2014) Reducing. World Appl Sci J 31(9):1601-1606

Volodchenko AA, Lesovik VS, Volodchenko AN, Glagolev ES, Zagorodnjuk LH, Pukharenko YV (2016) Int J Pharm Technol 8(3):18856-18867

Volodchenko AA, Lesovik VS, Volodchenko AN, Zagorodnjuk LH (2015) Int J Appl Eng Res 10(24):45142-421149

Volodchenko AN, Lesovik VS (2008a) Increasing production efficiency of autoclave materials. In: Proceedings of the higher educational institutions. Building, vol 9, pp 10-16

Volodchenko AN, Lesovik VS (2008b) Autoclave silicate materials with nanometer-sized materials. Build Mater 11:42-44

Volodchenko AN (2011) Features magnesia clay interaction with the calcium hydroxide in the synthesis and the formation of tumors microstructure. Bulletin of Belgorod State Technological University. VG Shukhov, vol 2, pp 51-55

Open Access This chapter is licensed under the terms of the Creative Commons Attribution 4.0 International License (http://creativecommons.org/licenses/by/4.0/), which permits use, sharing, adaptation, distribution and reproduction in any medium or format, as long as you give appropriate credit to the original author(s) and the source, provide a link to the Creative Commons license and indicate if changes were made.

The images or other third party material in this chapter are included in the chapter's Creative Commons license, unless indicated otherwise in a credit line to the material. If material is not included in the chapter's Creative Commons license and your intended use is not permitted by statutory regulation or exceeds the permitted use, you will need to obtain permission directly from the copyright holder.

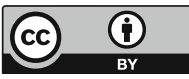

